\title{
Effect of a Setup without Machine Stop in a Multi-item Process Production System
}

\author{
Manabu Yamazaki *, Aya Ishigaki ${ }^{\dagger}$, \\ Munenori Kakehi :
}

\begin{abstract}
Recently, due to the diversification of market needs, production plants are shifting to multi-item small-volume production. However, frequent item switching in a single facility increases the setup time, resulting in a decrease in the production rate or the operational ratio of facilities. In this study, we consider a process production scheduling for a factory with a long setup time that produces multiple variants of garbage bags. In the experiment, several item-switching patterns were set on the basis of actual examples, and the influence of the differences in the setup method in continuous production of difficult-to-process products on the production time and setup time was investigated. Based on the comparison to the conventional production schedule, it is possible to improve the production time and setup time without increasing the loss by changing the setup method.
\end{abstract}

Keywords: Multi-item, Process production, Produciton sequence, Setup time

\section{Introduction}

In general, two production modes are used in building a production management system [1][2]. The first is assembly production, and the second is process production. In assembly production, many types of parts are processed and then hierarchically assembled into a final product. Conversely, in process production, chemical and physical treatment is applied after materials are added, and products are produced continuously. Because process production can produce many products in a short period of time and due to the strong effort to recycle products such as plastics as raw materials for other products in order to alleviate environmental impact, process production has attracted the attention of many companies [3][4]. In addition, as the performance of $3 \mathrm{D}$ printers has improved, companies have begun to incorporate process production with $3 \mathrm{D}$

\footnotetext{
* Acteiive Corporation, Chiba, Japan

$\dagger$ Tokyo University of Science, Chiba, Japan

* Fukushima University, Fukushima, Japan
} 
printers into the manufacturing process and at the prototyping stage [5] [6]. However, the switching of product lot for manufacturing of multiple items may require cleaning and manual adjustment of machinery. Therefore, the setup time for the process-production mode is very long compared to the standard assembly production. In addition, the time required for the adjustment of machinery differs widely based on the ability and processing status of the worker, giving rise to a high level of uncertainty. Therefore, in recent years, attention has been focused on the setup and maintenance of machinery by using robots and artificial intelligence, but this approach has not been widely introduced due to its high cost of development and installation in facilities and systems [7].

Conversely, driven by the recent intensification of competition and diversification of customer needs, companies need to answer requests from many customers in a short period of time. The transition to a multi-item small-quantity production is being performed at the production site. However, frequent switching of lots in a single facility results in an increase in setup time, which leads to a decrease in the production rate of the facility. Therefore, to accept a large number of customer orders, companies have been forced to produce large product lots and maintain a large inventory for each product.

Several previous studies have addressed many multi-item production systems. In the case of assembly production, it is necessary to allocate work to each process in consideration of the commonality and similarity of parts and work in the multi-item production, work-time difference between products, work-time variation, and so on [8][9][10][11][12][13]. Conversely, as part of ongoing research on production systems similar to process production for multiple items, scheduling by lot sizes and on insertion order considering the setup time has been studied [14][15][16][17]. It is known that production efficiency becomes worse for a small lot size, and the lot size for the relations of the trade-off that stock increases if big and the optimization of the production schedule are handled, but a study that considered the difference at the making arrangements time by the difference of the parts (material) by the variation of the product of the process product characteristic was not performed.

In this work, we study the production process of plastic garbage bags made of eco-friendly materials of Company A as an example. In other words, the plastic garbage bags of Company A are effective not only for reducing the $\mathrm{CO}_{2}$ emissions during incineration but also for recycling from products to raw materials. Currently, Company A switches products for production weekly to avoid a half-day setup. However, for a week-long continuous production, this company maintains a large amount of inventory in the warehouse. These product characteristics motivate us to consider performing the setup while operating the machine. We consider the production process of changing the setup while the machine is in operation. Here several item-switching patterns are set based on actual examples, and the influence on setup time and inventory quantity for each pattern is examined.

\section{Process production model}

We first explain how the environmentally friendly plastic garbage bags are handled in this study and the manufacturing process. 


\subsection{Plastic garbage bags using eco-friendly materials}

Reduction of expenses related to waste disposal is a significant problem for local governments. For example, garbage disposal costs in 2013 accounted for approximately 5\% of the municipal budget in the Chiba prefecture. Therefore, in Chiba-Shi, we examine the appropriate pricing of plastic garbage bags and seek to reduce the amount of garbage by adjusting the cost of the plastic garbage bags [18]. Conversely, the amount of incinerated garbage has decreased slightly because garbage is thoroughly sorted for recycling. However, for smooth execution of recycling activities, a thorough classification of the garbage is required. Therefore, each local government has approached this problem by using measures such as setting up collection bags for different types of garbage. Not only is the classification method of the garbage different for every local government but also the performance of the incinerators vary. Thus, the standard size and color of the plastic garbage bag also vary. Not only the printed label but also the plastic garbage bag handles differ, and there are many makers producing many types of plastic garbage bags.

In recent years, the reduction rate of the amount of refuse in municipalities has reached capacity, and further reduction is being pursued due to environmental considerations. Therefore, some municipalities use vinyl as an environment-conscious material for the designated plastic garbage bags and struggle to reduce the environmental impact at the time of combustion. Overall, the requirement to use the designated plastic garbage bags and the standard for the environmental impact are different for every local government. Moreover, the factory producing plastic garbage bags produces plastic garbage bags with a great variety of material, size, and functions while changing items.

\subsection{Product composition of plastic garbage bags}

The plastic garbage bag is different in material (color), size, and print as described in section 2.1 section. Every local government directs the plastic garbage bag maker to produce the bag according to the specifications from each local government.

Table 1 shows a part of the specifications considered by every local government and the product of the plastic garbage bag for which Company A produces plastic garbage bags handles. The raw materials of all products use the same colorless base resin, but the presence or absence of coloring of plastic garbage bags varies depending on the requirements of the local governments and even by flammability/incombustibility. Moreover, plastic garbage bags are designed differently by different municipalities, and more than one size (capacity) is specified. Therefore, semi-finished products will be produced for each of them because the contents of the printing surface of the vinyl garbage bag and the printing color are different for each municipality due to flammability and incombustibility requirements. Furthermore, the amount of plastic garbage bags to be used depends on the population and the lifestyle of the residents of the city; thus, the amount of demand varies greatly among local governments.

In recent years, due to diversification of customer needs in the manufacturing industry, not only design but also characteristics such as color variation, size variation, and specification variation are diversifying. Moreover, the number of items handled is increasing. In this case, the general production process makes the basic design of the product equivalent for all variations. This allows diversification in the differences of the bag exteriors and some 
module parts. Thus, producers can plan the facilitation of production for the simplification of product design and cost reduction by the commonization of the parts. In the garbage collection business, it is expected that there will be further progress in the separation of the waste. This encourages local governments to introduce or re-examine the cost of plastic garbage bags; thus, the factories that produce the plastic garbage bags are faced with the need to respond to a further variation in product specifications.

Table 1: Local government specifications for the plastic garbage bag

\begin{tabular}{|c|c|c|c|c|c|}
\hline \multirow[b]{2}{*}{ Municipality } & \multirow[b]{2}{*}{$\begin{array}{l}\text { Material } \\
\text { (color) }\end{array}$} & \multicolumn{3}{|c|}{ Size } & \multirow[b]{2}{*}{$\begin{array}{c}\text { Printing } \\
\text { color }\end{array}$} \\
\hline & & $\begin{array}{c}\text { Capacity } \\
\text { (L) }\end{array}$ & $\begin{array}{l}\text { Width } \\
\text { (mm) }\end{array}$ & $\begin{array}{c}\text { Original } \\
\text { Width }(\mathrm{mm})\end{array}$ & \\
\hline \multirow{8}{*}{ A } & \multirow{4}{*}{$\begin{array}{l}\text { Flammable } \\
\text { (yellow) }\end{array}$} & 40 & 450 & 650 & \multirow{4}{*}{ Red } \\
\hline & & 30 & 350 & 550 & \\
\hline & & 20 & 330 & 500 & \\
\hline & & 10 & 260 & 400 & \\
\hline & \multirow{4}{*}{$\begin{array}{l}\text { Incombustible } \\
\text { (green) }\end{array}$} & 40 & 450 & 650 & \multirow{4}{*}{ Navy } \\
\hline & & 30 & 350 & 550 & \\
\hline & & 20 & 330 & 500 & \\
\hline & & 10 & 260 & 400 & \\
\hline \multirow{4}{*}{ B } & \multirow{2}{*}{$\begin{array}{l}\text { Flammable } \\
\text { (clear) }\end{array}$} & 40 & 450 & 650 & \multirow{2}{*}{ Red } \\
\hline & & 20 & 330 & 500 & \\
\hline & \multirow{2}{*}{$\begin{array}{l}\text { Incombustible } \\
\text { (clear) }\end{array}$} & 40 & 450 & 650 & \multirow{2}{*}{ Navy } \\
\hline & & 20 & 330 & 500 & \\
\hline
\end{tabular}

\subsection{Manufacturing process of plastic garbage bags}

Company A factory manufactures plastic garbage bags in roughly four steps (Figure. 1). A buffer is set between each step.
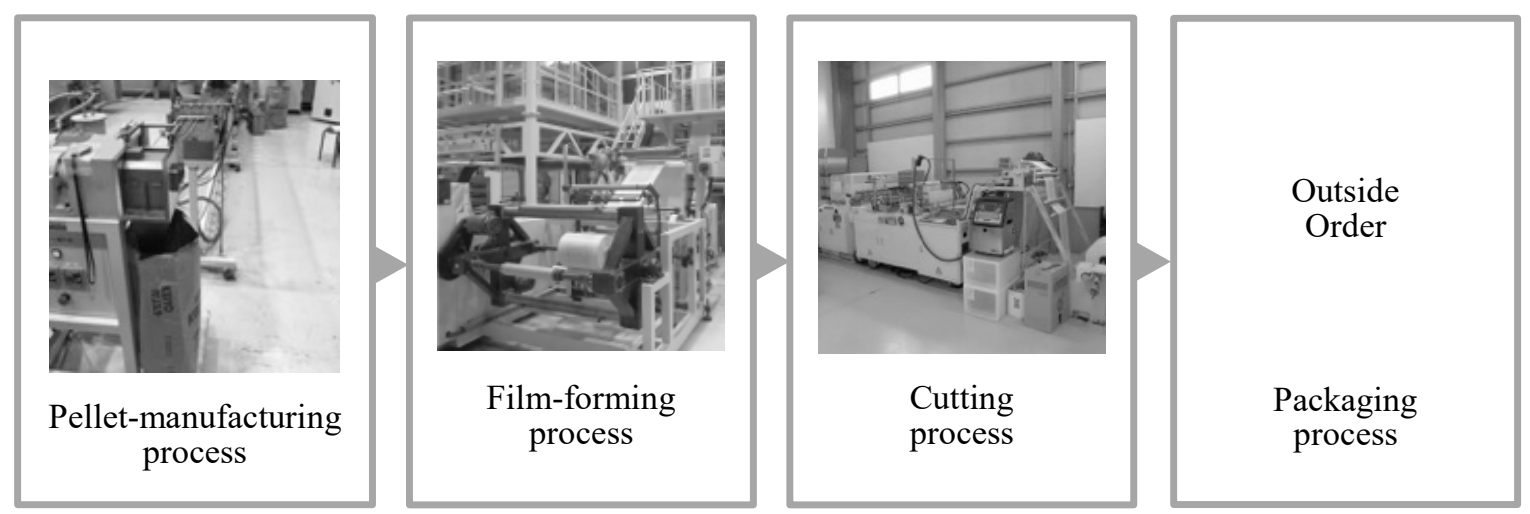

Figure 1: Manufacturing process for plastic garbage bags of Company A 


\subsubsection{Pellet-manufacturing process}

The pellets are made into particles of around $3-5 \mathrm{~mm}$ for easy processing, and base resin is produced in the pellet-manufacturing process. In the pellet-manufacturing process, an instrument called KOMA is used to knead the raw materials, with a different shape of KOMA used for each raw material. The cleaning and installation of KOMA during a product changeover is time consuming. The produced base resin is temporarily placed and transported to the film-forming step as necessary.

\subsubsection{Film-forming process}

In the film-forming process, cylindrical vinyl rolls from pellets are produced by a film-molding machine according to the specifications of each municipality (Figure. 2). Here a cylindrical vinyl is generated from the pellets, and the letter designated by the municipality is printed in the designated color and position. Because the characters are finely restricted for the location to be printed, at the time of product switching, not only a change in the size of the bag is required, but also a lot of time is necessary to adjust the print position. Furthermore, since the printing position shifts even during continuous production, it is necessary to conduct repeated fine adjustments during the manufacture. Currently, if the film-forming machine is stopped and the printing position is adjusted, the number of defective products is reduced, but the stop time (time to finish production and clean up until the machine is completely stopped) and the rise time (time to prepare the material, move the machine and start production) shown in Table 2 are required respectively to stop the machine and to again use it for manufacturing. Therefore, the worker stops and adjusts the machine. Alternatively, it is necessary to evaluate under continuous observation whether to make fine adjustments while operating the machine despite the occurrence of a defective product loss to avoid the stop and rise time of approximately $8 \mathrm{~h}$. For Company A, it is proposed to operate the machine continuously for five days a week. In this case, the machine is started at the beginning of the week and the production of vinyl garbage bags is stopped by stopping the machine on the weekend, with all adjustments of the print position performed during machine operation.

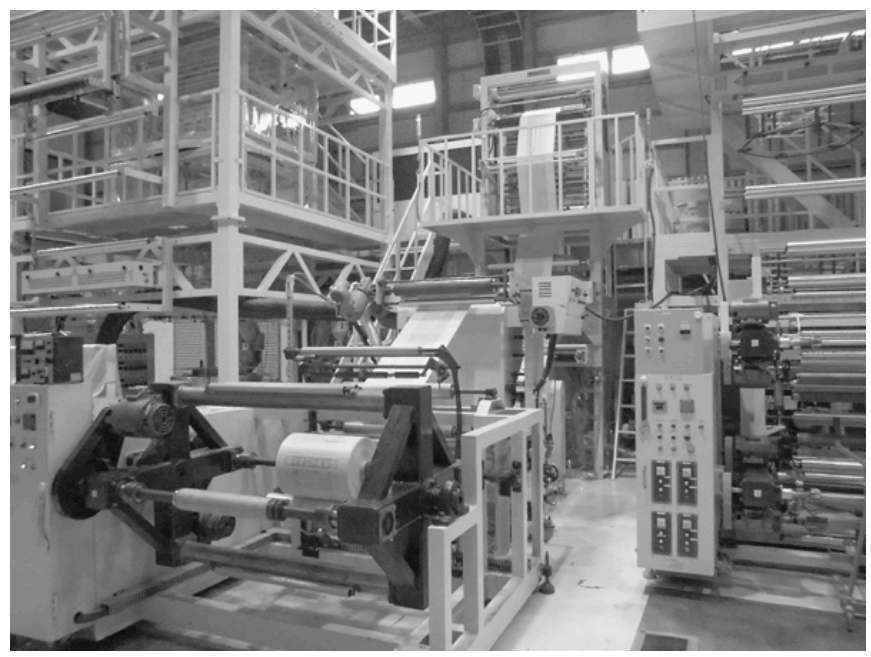

Figure 2: Film-forming machine 


\subsubsection{Cutting process}

In the cutting process, the vinyl roll is cut by a cutting machine into a single bag according to the design specified by each municipality (Figure. 3), and an operation is performed to fold the vinyl roll every specified number of sheets. In the cutting process, it is necessary to adjust the cutting position and the attachment and detachment of the vinyl roll at the time of switching of the items. Furthermore, it is necessary to adjust the cutting position even during production. Table 3 shows the time required for starting up and shutting down the cutting machine. Because the start-up/shut-down time is less than the film-forming step, switching is frequently performed compared to the film-forming process. However, as in the film-molding process, the worker stops and adjusts the machine and the worker a will be forced to make a decision as to whether to make fine adjustments during the manufacturing despite the occurrence of losses.

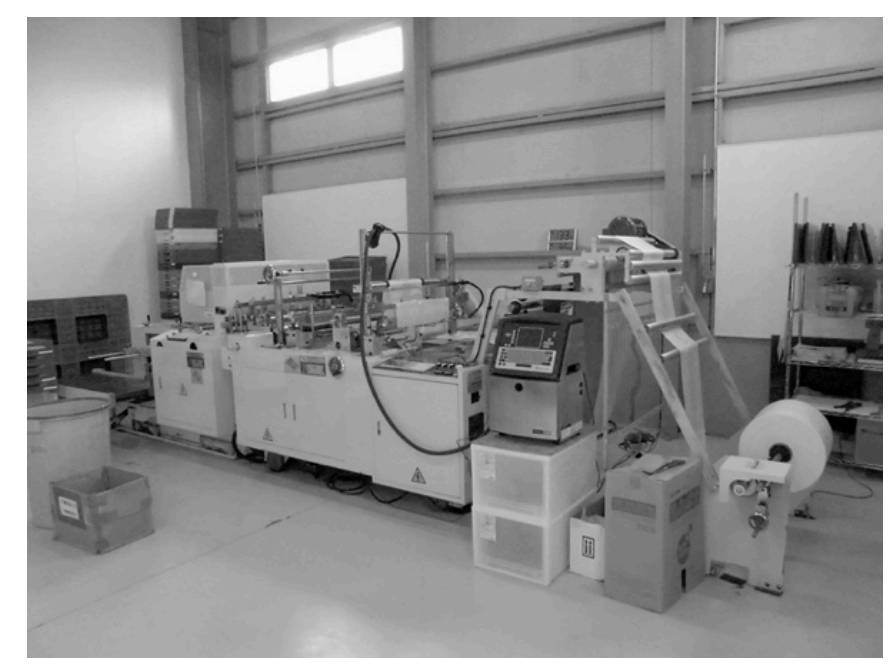

Figure 3: Cutting machine

\subsubsection{Packaging process}

In the final packaging process, the folded plastic bag is placed in the outer bag, and the operation of packing into the cardboard is performed. The factory is currently outsourcing these tasks to welfare organizations.

Because the time for making arrangements for the pellet-manufacturing process and the film-molding process in the plastic garbage bag process of manufacture of this study is longer than that described above, the change of the items is reduced to reduce the loss during the preparation. Because of the small number of setups, this results in having much stock among these processes. Furthermore, because the worker performs the adjustment of the position in the film molding and the cutting processes under the present conditions without stopping the machine, greater production is necessary to compensate for the anticipated production loss by the adjustment of these upper level processes to produce slightly more than the requirement so that more stock is maintained. In general, the stock quantities increase because an item is divided so as to go for down-stream process by the process production, but manufacturing process in which this research has been the subject has become a result of facing a large amount of stock in the upstream in order to allow the production loss for the adjustment. 
Table 2: Estimated start-up time and shut-down times of the machine in the film-forming process

\begin{tabular}{|c|c|c|c|}
\hline Municipality & $\begin{array}{l}\text { Material } \\
\text { (color) }\end{array}$ & $\begin{array}{l}\text { Capacity } \\
\text { (L) }\end{array}$ & Time (h) \\
\hline \multirow{8}{*}{ A } & \multirow{4}{*}{$\begin{array}{c}\text { Flammable } \\
\text { (yellow) }\end{array}$} & 40 & 4 \\
\hline & & 30 & 4 \\
\hline & & 20 & 4 \\
\hline & & 10 & 4 \\
\hline & \multirow{4}{*}{$\begin{array}{l}\text { Incombustible } \\
\text { (green) }\end{array}$} & 40 & 4 \\
\hline & & 30 & 4 \\
\hline & & 20 & 4 \\
\hline & & 10 & 4 \\
\hline \multirow{4}{*}{ B } & \multirow{2}{*}{$\begin{array}{l}\text { Flammable } \\
\text { (clear) }\end{array}$} & 40 & 4 \\
\hline & & 20 & 4 \\
\hline & \multirow{2}{*}{$\begin{array}{l}\text { Incombustible } \\
\text { (clear) }\end{array}$} & 40 & 4 \\
\hline & & 20 & 4 \\
\hline
\end{tabular}

Table 3: Estimated start-up time and the shut-down time of the machine in the cutting process

\begin{tabular}{|c|c|c|c|}
\hline Municipality & $\begin{array}{l}\text { Material } \\
\text { (color) }\end{array}$ & $\begin{array}{l}\text { Capacity } \\
\text { (L) }\end{array}$ & $\begin{array}{c}\text { Start-up } \\
\text { time/Shut-down } \\
\text { time (min) }\end{array}$ \\
\hline \multirow{8}{*}{ A } & \multirow{4}{*}{$\begin{array}{c}\text { Flammable } \\
\text { (yellow) }\end{array}$} & 40 & $90 / 40$ \\
\hline & & 30 & $90 / 40$ \\
\hline & & 20 & $90 / 40$ \\
\hline & & 10 & $90 / 40$ \\
\hline & \multirow{4}{*}{$\begin{array}{c}\text { Incombustible } \\
\text { (green) }\end{array}$} & 40 & $90 / 40$ \\
\hline & & 30 & $90 / 40$ \\
\hline & & 20 & $90 / 40$ \\
\hline & & 10 & $90 / 40$ \\
\hline \multirow{4}{*}{ B } & \multirow{2}{*}{$\begin{array}{c}\text { Flammable } \\
\text { (clear) }\end{array}$} & 40 & $90 / 40$ \\
\hline & & 20 & $90 / 40$ \\
\hline & \multirow{2}{*}{$\begin{array}{l}\text { Incombustible } \\
\text { (clear) }\end{array}$} & 40 & $90 / 40$ \\
\hline & & 20 & $90 / 40$ \\
\hline
\end{tabular}

\section{Influence of switching pattern on setup time}

All of the defective products that occur in the course of the production of plastic garbage bags that are considered in this study are returned to the raw material state, and then, it is possible to use them as a raw material for some other type of product. Therefore, when a problem occurs during continuous production, to prevent loss due to setup time, adjustment is made without 
stopping the machine while allowing loss due to defective products to be generated during the adjustment during the film-forming and cutting processes. However, because these adjustment operations are usually performed at the time of starting up, it is considered that it is possible to reduce the setup time by doing work without stopping the machine. Therefore, to create seven item-switching patterns, we investigated the time effect when performing a product changeover without stopping the machine in Factory A.

Currently, we produce one item per week ( 5 days: $120 \mathrm{~h}$ ) and then carry out the change of the item by scheduling the starting time and shutting-down time around a holiday (Figure. 4). Therefore, we investigated the influence of item switching under the situation where continuous production is possible within two production cycles $(240 \mathrm{~h})$.

\begin{tabular}{l|c|c|c|c|c|}
\multicolumn{3}{l}{ Mon-Fri $120 \mathrm{~h}$} & Mon-Fri $120 \mathrm{~h}$ \\
\hline start & Production & stop holiday & start & Production & stop holiday
\end{tabular}

Figure 4: Current cycle

\subsection{Effect by switching items without stopping the machine}

To investigate the effect and loss due to item switching during manufacturing in Company A's film-forming and cutting processes, the items were switched without stopping the machine with the seven switching patterns shown in Table 4. As shown in Figure 5, continuous production for $240 \mathrm{~h}$ was set as one production cycle, and item switching was performed once without stopping the machine. The times for making arrangements required for the item change of the seven patterns in the cutting process are shown in Table 6, and the time for the seven patterns used in the film-molding process are presented in Table 5. In addition, Tables 7 and 8 show the production time according to the state and the current experiment during $240 \mathrm{~h}$ (two production cycles). The lost time includes the time occurring due to the adjustment of the print position during consecutive production at these production times, but we decided to include it in these loss times and to evaluate it because these losses showed approximately the same frequency.

$240 \mathrm{~h}$

\begin{tabular}{|l|l|l|l|l|}
\hline start & Production & switch & Production & stop \\
\hline
\end{tabular}

Figure 5: Cycle of continuous production 
Table 4: Pattern of product changeover in manufacturing

\begin{tabular}{|c|c|}
\hline Switching method & Switch type \\
\hline When the size is different & A-I40 $\rightarrow$ A-I30 \\
\hline When the material is different & A-I40 $\rightarrow$ A-F40 \\
\hline When the size and material are different & A-I40 $\rightarrow$ A-F30 \\
\hline When the municipality is different & A-I40 $\rightarrow$ B-I40 \\
\hline When the municipality and size are different & A-I40 $\rightarrow$ B-I20 \\
\hline When the municipality and material are different & A-I40 $\rightarrow$ B-F40 \\
\hline When the municipality, size and material are different & A-I40 $\rightarrow$ B-F20 \\
\hline
\end{tabular}

A: Municipality A, B: Municipality B, I: Flammable, F: Incombustible, 40: 40L, 20: 20L

Table 5: Time required for item switching during manufacturing (for film-forming process)

\begin{tabular}{|c|c|}
\hline Switching method & Setup time (h) \\
\hline When the size is different & 1.5 \\
\hline When the material is different & 2.5 \\
\hline When the size and material are different & 3 \\
\hline When the municipality is different & 1.5 \\
\hline When the municipality and size are different & 2 \\
\hline When the municipality and material are different & 3.5 \\
\hline When the municipality, size and material are different & 4 \\
\hline
\end{tabular}


Table 6: Time required for item switching during manufacturing (in case of cutting process)

\begin{tabular}{|c|c|}
\hline Switching method & Setup time (min) \\
\hline When the size is different & 9 \\
\hline When the material is different & 90 \\
\hline When the size and material are different & 10 \\
\hline When the municipality is different & 90 \\
\hline When the municipality and size are different & 10 \\
\hline When the municipality and material are different & 90 \\
\hline When the municipality, size and material are different & 2 \\
\hline
\end{tabular}

Table 7: Change in production time of film-forming process

\begin{tabular}{|c|c|c|}
\hline Switching method & $\begin{array}{c}\text { Current cycle } \\
(\mathrm{h})\end{array}$ & $\begin{array}{c}\text { Cycle of continuous } \\
\text { production (h) }\end{array}$ \\
\hline When the size is different & 224 & 230.5 \\
\hline When the material is different & 224 & 229.5 \\
\hline When the size and material are different & 224 & 229 \\
\hline When the municipality is different & 224 & 230.5 \\
\hline $\begin{array}{c}\text { When the municipality and size are } \\
\text { different }\end{array}$ & 224 & 228.5 \\
\hline $\begin{array}{c}\text { When the municipality and material are } \\
\text { different }\end{array}$ & 224 & 228 \\
\hline $\begin{array}{c}\text { When the municipality, size and } \\
\text { material are different }\end{array}$ & 224 & \\
\hline
\end{tabular}


Table 8: Change in production time of cutting process

\begin{tabular}{|c|c|c|}
\hline Switching method & Current cycle (h) & $\begin{array}{c}\text { Cycle of continuous } \\
\text { production (h) }\end{array}$ \\
\hline When the size is different & 235.7 & 236.4 \\
\hline When the material is different & 235.7 & 237.5 \\
\hline When the size and material are different & 235.7 & 236.4 \\
\hline When the municipality is different & 235.7 & 237.7 \\
\hline $\begin{array}{c}\text { When the municipality and size are } \\
\text { different }\end{array}$ & 235.7 & 236.4 \\
\hline $\begin{array}{c}\text { When the municipality and material are } \\
\text { different }\end{array}$ & 235.7 & 237.7 \\
\hline $\begin{array}{c}\text { When the municipality, size and } \\
\text { material are different }\end{array}$ & 235.7 & 236.4 \\
\hline
\end{tabular}

Table 9: Production volume for each item in film-forming process (for continuous operation for five days a week)

\begin{tabular}{|c|c|c|c|}
\hline Municipality & $\begin{array}{l}\text { Material } \\
\text { (Color) }\end{array}$ & Capacity (L) & $\begin{array}{l}\text { Production volume continuously } \\
\text { operating for five days a week } \\
\text { (m) }\end{array}$ \\
\hline \multirow{8}{*}{ A } & \multirow{4}{*}{$\begin{array}{l}\text { Flammable } \\
\text { (yellow) }\end{array}$} & 40 & $2000 \times 50$ \\
\hline & & 30 & $2000 \times 60$ \\
\hline & & 20 & $2000 \times 65$ \\
\hline & & 10 & $2000 \times 75$ \\
\hline & \multirow{4}{*}{$\begin{array}{l}\text { Incombustible } \\
\text { (green) }\end{array}$} & 40 & $2000 \times 50$ \\
\hline & & 30 & $2000 \times 60$ \\
\hline & & 20 & $2000 \times 65$ \\
\hline & & 10 & $2000 \times 75$ \\
\hline \multirow{4}{*}{ B } & \multirow{2}{*}{$\begin{array}{l}\text { Flammable } \\
\text { (clear) }\end{array}$} & 40 & $2000 \times 50$ \\
\hline & & 20 & $2000 \times 65$ \\
\hline & \multirow{2}{*}{$\begin{array}{c}\text { Incombustible } \\
\text { (clear) }\end{array}$} & 40 & $2000 \times 50$ \\
\hline & & 20 & $2000 \times 65$ \\
\hline
\end{tabular}


Table 10: Production volume for each item in cutting process (for continuous operation for five days a week)

\begin{tabular}{|c|c|c|c|}
\hline Municipality & $\begin{array}{l}\text { Material } \\
\text { (Color) }\end{array}$ & Capacity (L) & $\begin{array}{l}\text { Production volume continuously } \\
\text { operating for five days a week }\end{array}$ \\
\hline \multirow{8}{*}{ A } & \multirow{4}{*}{$\begin{array}{l}\text { Flammable } \\
\text { (yellow) }\end{array}$} & 40 & 30,000 \\
\hline & & 30 & 30,000 \\
\hline & & 20 & 30,000 \\
\hline & & 10 & 30,000 \\
\hline & \multirow{4}{*}{$\begin{array}{c}\text { Incombustible } \\
\text { (green) }\end{array}$} & 40 & 30,000 \\
\hline & & 30 & 30,000 \\
\hline & & 20 & 30,000 \\
\hline & & 10 & 30,000 \\
\hline \multirow{4}{*}{ B } & \multirow{2}{*}{$\begin{array}{l}\text { Flammable } \\
\text { (clear) }\end{array}$} & 40 & 30,000 \\
\hline & & 20 & 30,000 \\
\hline & \multirow{2}{*}{$\begin{array}{c}\text { Incombustible } \\
\text { (clear) }\end{array}$} & 40 & 30,000 \\
\hline & & 20 & 30,000 \\
\hline
\end{tabular}

Table 11: Steps required for item switching during manufacturing (for film-forming process)

\begin{tabular}{|c|c|c|c|c|c|c|}
\hline Switching method & $\begin{array}{c}\text { Material } \\
\text { preparation }\end{array}$ & $\begin{array}{l}\text { Heater } \\
\text { setting } \\
\text { of } \\
\text { machine }\end{array}$ & $\begin{array}{l}\text { Size } \\
\text { adjustm } \\
\text { ent }\end{array}$ & $\begin{array}{l}\text { Ink } \\
\text { prepara } \\
\text { tion }\end{array}$ & $\begin{array}{l}\text { Prepara } \\
\text { tion for } \\
\text { printing }\end{array}$ & $\begin{array}{l}\text { Product } \\
\text { adjustm } \\
\text { ent }\end{array}$ \\
\hline When the size is different & ० & - & ० & - & ○ & ○ \\
\hline $\begin{array}{c}\text { When the material is } \\
\text { different }\end{array}$ & 0 & - & - & 0 & 0 & O \\
\hline $\begin{array}{l}\text { When the size and } \\
\text { material are different }\end{array}$ & ○ & - & 0 & 0 & 0 & O \\
\hline $\begin{array}{c}\text { When the municipality is } \\
\text { different }\end{array}$ & 0 & - & - & - & 0 & 0 \\
\hline $\begin{array}{l}\text { When the municipality } \\
\text { and size are different }\end{array}$ & 0 & - & 0 & - & 0 & O \\
\hline $\begin{array}{l}\text { When the municipality } \\
\text { and material are different }\end{array}$ & O & - & - & 0 & 0 & O \\
\hline $\begin{array}{c}\text { When the municipality, } \\
\text { size and material are } \\
\text { different }\end{array}$ & 0 & - & O & O & O & O \\
\hline
\end{tabular}


As a result of the experiments, in all the patterns in the film-forming process, switching times of $8 \mathrm{~h}$ usually occurred, but the item switching could be completed within $4 \mathrm{~h}$. Generally, the starting process contains the steps of material preparation, mechanical heater arrangement, product size adjustment, ink preparation, printing preparation, and product adjustment. However, when product switching was performed without stopping the machine, the order of the steps required for the product change and a starting process may change, obtaining a reduced setup time (see Table 11). As a result, the production time could be increased up to $6.5 \mathrm{~h}$ in the film-forming process. Based on rough estimation from the production amount when operating for five consecutive days per item in each item shown in Table 9, this means that it was possible to produce as much as 1.45 worth of $2000 \mathrm{~m}$ volume. Conversely, by switching the item without stopping the machine, 0.22 loss per hour will be generated. The largest switching time is obtained due to the change in the material (combustible/incombustible). This is considered to be caused by the fact that it takes time to adjust the color and position in the process of printing the characters on the plastic garbage bag as the material is changed, but since this work is carried out with the machine in operation even for a normal start up, the amount of defective products does not change in practice.

Table 12: Steps required for item switching during manufacturing (for cutting process)

\begin{tabular}{|c|c|c|c|c|c|c|}
\hline Switching method & $\begin{array}{c}\text { Material } \\
\text { preparation }\end{array}$ & $\begin{array}{c}\text { Heater } \\
\text { setting } \\
\text { of } \\
\text { machine }\end{array}$ & $\begin{array}{c}\text { Size } \\
\text { adjustm } \\
\text { ent }\end{array}$ & $\begin{array}{c}\text { Setting } \\
\text { of } \\
\text { printer }\end{array}$ & $\begin{array}{c}\text { Replace } \\
\text { ment of } \\
\text { cutter }\end{array}$ & $\begin{array}{c}\text { Product } \\
\text { adjustm } \\
\text { ent }\end{array}$ \\
\hline When the size is different & $\circ$ & - & $\circ$ & - & $\circ$ & $\circ$ \\
\hline $\begin{array}{c}\text { When the material is } \\
\text { different }\end{array}$ & $\circ$ & - & - & - & $\circ$ & $\circ$ \\
\hline $\begin{array}{c}\text { When the size and } \\
\text { material are different }\end{array}$ & $\circ$ & - & $\circ$ & - & $\circ$ & 0 \\
\hline $\begin{array}{c}\text { When the municipality is } \\
\text { different }\end{array}$ & 0 & - & - & - & 0 & 0 \\
\hline $\begin{array}{c}\text { When the municipality } \\
\text { and size are different }\end{array}$ & $\circ$ & - & $\circ$ & - & $\circ$ & $\circ$ \\
\hline $\begin{array}{c}\text { When the municipality } \\
\text { and material are different }\end{array}$ & $\circ$ & - & - & - & $\circ$ & $\circ$ \\
\hline $\begin{array}{c}\text { When the municipality, } \\
\text { size and material are } \\
\text { different }\end{array}$ & $\circ$ & - & $\circ$ & - & $\circ$ & $\circ$ \\
\hline
\end{tabular}

In the cutting process, the steps of the starting process are material preparation, mechanical heater arrangement, starting of a printer, exchange of a cutter, size adjustment, and product adjustment. However, when product switching was performed without stopping the machine, the order of the steps in the starting process may change, obtaining a reduced setup time (see Table 
12). In the cutting process, when the machine is stopped, about two hours of start-up/shut-down time is required, so even if the machine is operated while switching, the production time does not increase much. Therefore, further analysis is necessary for the effect of changing the switching pattern in the cutting process.

\subsection{Changes in inventory due to changes in number of item switching}

Company A currently carries out item switching every week, so it is supposed to maintain a large amount of inventory. However, although manufacturing loss occurs by switching the item without stopping the machine, items can be switched within the week by controlling the switching pattern in the film-forming process making it possible to switch the items after production for one day. As a result, it is anticipated that the inventory will be reduced below the current inventory amount, but since the switching time will change according to the capabilities and current status of workers, further data collection and analysis will be required in the future.

\section{Conclusion}

In this study, we investigated the influence of differences in item-switching methods in a process-production schedule with a long setup time in stages, taking a factory of Company A that manufactures plastic garbage bags using environmentally friendly materials as an example. Currently, Company A switches items weekly to reduce the set-up time. However, as a result of trying a method of switching items without stopping the machine, depending on the switching pattern, it was possible to switch the item with a short switching time.

Currently, Company A has a work schedule in which workers with high abilities are in charge of change-over and item change, and the survey in this study was also carried out using the high-ability workers. However, to examine the further use of small-lot production in the future it will be necessary to take into account the differences in the workers' ability. Furthermore, in order to reduce the setup time itself, in view of variations in the material, it is necessary to standardize the waste plastic bag parts (Material). Cooperation of local governments is required for implementation of this step, but based on the results of this survey, it is expected that the following three measures will be effective in reducing the setup time.

(1) Standardize different materials (bag color, formulation) among the local governments. Standardization of each flammable/incombustible standard to a common standard including combustible/incombustible. This is effective for improving efficiency of the film-forming process.

(2) Standardize the size of plastic garbage bags among the municipalities and use a common roll width (original width) of the vinyl roll before the cutting process. This is effective for improving the efficiency of the cutting process.

(3) Standardize print colors of plastic garbage bags. Standardize every flammable/incombustible and print colors common to all products. This is effective for improving the efficiency of the film-forming process. 
In this research, only the reduction effect of the breaking-down time by the combination of a product was investigated. However, a product-switching schedule is closely related to the demand. That is, it is possible to reduce the volume of inventories of a product by performing the production according to the frequency of demand. Conversely, the reduction of the setup time by controlling the product combination described in this work will result in a reduction of work-in-process inventory [19][20]. In the future, we plan to carry out production-lot scheduling and inventory evaluation based on the results of this survey.

\section{Acknowledgement}

This research was partially supported by the Japan Society for the Promotion of Science (JSPS), KAKENHI, Grant-in-Aid for Scientific Research (C), 16K01262. The authors would like to thank Acteiive Corporation for providing information on the real production system.

\section{References}

[1] F. A. Abdulmalek, J. Rajgopal, "Analyzing the benefits of lean manufacturing and value stream mapping via simulation: A process sector case study", International Journal of Production Economics, Vol. 107, No. 1, 2007, pp. 223-236

[2] T. Enkawa, M. Kuroda, Y. Fukuda, "Dictionary of production control”, Asakura Publishing Co., Ltd. 1999, in Japanese.

[3] Canon website, Canon Cartridge Recycling Programme; https://www.canon.co.uk/recycling/ (2017.2.8 Reading)

[4] Ricoh website, Recycling; https://www.ricoh.com/tgos/detail2_3.html (2017.2.8 Reading)

[5] Stratasys website; http://www.stratasys.com/en (2017.2.8 Reading)

[6] Altech website; http://www.altech.co.jp/eng/works/ (2017.2.8 Reading)

[7] Ministry of Economy, Trade and Industry website, Robot introduction demonstration project - case study handbook 2016 - Ministry of Economy, Trade and Industry, in Japanese; http://www.meti.go.jp/report/whitepaper/20160426001.html (2016.2.8 Reading)

[8] C. A. Yano and R. Rachamadugu, "Sequencing to minimize work overload in assembly lines with product options", Management Science, Vol. 37, No. 5, 1991, pp. 572-586

[9] Z. Xiaobo and K. Ohno, "Algorithms for sequencing mixed models on an assembly line in a JIT production system”, Computers \& Industrial Engineering, Vol. 32, No. 1, 1997, pp. 4756

[10] Y. Shimizu, T. Waki and J. K. Yoo, "Multi-objective analysis for a sequencing planning of mixed-model assembly line, Control and Information", Vol. 22, No. 2, 2009, pp. 49-57

[11] N. T. Thomopoulos, "Line balancing-sequencing for mixed-model assembly", Management Science, Vol. 14, No. 2, 1967, pp. B59-B75 
[12] J. Bautista and A. Cano, "Solving mixed model sequencing problem in assembly lines with serial workstations with work overload minimization and interruption rules", European Journal of Operational Research, Vol. 210, No. 3, 2011, pp. 495-513

[13] A. Ishigaki and T. Miyashita, "Development of search method for sequencing problem in mixed-model assembly lines", Journal of Advanced Mechanical Design, Systems, and Manufacturing, Vol. 10, No. 3, 2016, DOI: 10.1299/jamdsm.2016jamdsm0048

[14] K. Muramatsu, "Simultaneous Optimization for Lot Sizing and Lot Sequencing: Multi-item Single Machine Lot Size Scheduling with Setup Time", Journal of Japan Industrial Management Association, Vol. 52, No. 5, 2001, pp. 313-321, in Japanese.

[15] H. Arai， S. Morito， J. Imaizumi, "A Column Generation Approach for Discrete Lotsizing and Scheduling Problem on Identical Parallel Machines", Journal of Japan Industrial Management Association, Vol. 55, No. 2, 2004, pp. 69-76, in Japanese.

[16] W. L. Maxwell, "The scheduling of economic lot sizes", Naval Research Logistics Quarterly, Vol. 11, No. 2, 1964, pp. 89-124.

[17] E. Levén and A.Segerstedt, "A schedulingpolicy for adjusting economic lot quantities to afeasible solution", European Journal of Operational Research, Vol. 179, No. 2, 2007, pp. $414-423$.

[18] Chiba Prefecture website, Chiba Prefecture Waste Processing Plan; https://www.pref.chiba.lg.jp/shigen/keikaku/kankyouseikatsu/haiki-sakutei.html $\quad$ (2016.2.8 reading)

[19] P. R. McMullen, Peter Tarasewich, "A beam search heuristic method for mixed-model scheduling with setups", International Journal of Production Economics, Vol. 96, No. 2, 2005, pp. $727-738$

[20] N. Boysen, M. Fliedner, A. Scholl, "Sequencing mixed-model assembly lines: Survey, classification and model critique", European Journal of Operational Research, Vol. 192, No. 2, 2009, pp. 349-373 